\title{
CHEMICAL COMPOUNDS AND BIOLOGICAL ACTIVITY OF AN EXTRACT FROM BOUGAINVILLEA $X$ BUTTIANA (VAR. ROSE) HOLTTUM AND STANDL
}

\author{
RIGOBERTO VILLANUEVA GUERRER0 ${ }^{1}$, RODOLFO ABARCA-VARGAS ${ }^{2}$, VERA L. PETRICEVICH \\ ${ }^{1}$ Facultad de Medicina de la Universidad Autónoma Del Estado de Morelos. Calle Iztaccihuatl Esq. Leñeros, Col. Volcanes, Cuernavaca, \\ Morelos, CP. 62350, ${ }^{2}$ Fellow Post Doctoral CONACyT Program \\ Email: vera.petricevich@uaem.mx \\ Received: 16 Nov 2016 Revised and Accepted: 09 Jan 2017
}

\begin{abstract}
Objective: A Bougainvillea x buttiana (var. Rose) Holttum and Standl extract (BxbREE) was prepared and its chemical composition, antioxidant and anti-inflammatory activity were evaluated.

Methods: For the analyses of the phytochemical compounds present in BxbREE extract, gas chromatography-mass spectrometry (GC/MS) was used. To explore the anti-oxidant, anti-inflammatory activities, total phenolic contents, carbohydrates, lipids and carrageenan-induce paw edema models, respectively, were used. For in vivo experiments, the extract was orally, intraperitoneally and/or subcutaneously administered at doses of $0.04,0.4$, 4 and $40 \mathrm{mg} / \mathrm{kg}$.

Results: GC/MS analyses showed the presence of 7 compounds, including 2-Propenoic acid, 3-(2-hydroxyphenyl)-, (E)-(1.19\%); 2-Methoxy-4vinylphenol (0.22\%); 3-0-Methyl-d-glucose (92.14\%); $n$-Hexadecanoic acid (0.76\%); Hexadecanoic acid, ethyl ester (1.17\%); 9,12-octadecadienoic acid, ethyl ester (1.93\%); and 9,12,15-Octadecatrienoic acid, ethyl ester (Z,Z,Z) (2.59\%). Phytochemical qualitative analysis showed the presence of total phenolic contents at $320 \mathrm{mg}$ of Gallic acid Equivalent/gram of dried extract (GA-Eq/g extract); carbohydrates $5.18 \mathrm{mg} / \mathrm{ml}$ and lipids 13.88 $\mathrm{mg} / \mathrm{ml}$. In accordance the structures the major compound was 3-0-Methyl-d-glucose. Our results also clearly indicate that BxbREE decreases inflammation in BALB/c mice as a subplantar injection of carrageenan-induced paw edema. The extract presented a potent dose-dependent inhibitory effect. The edema inhibition percentage was significantly lower in groups of animals treated with BxbREE by via intraperitoneal or subcutaneous when compared with those results obtained for groups treated by orally administration $(\mathrm{p}<0.001)$.
\end{abstract}

Conclusion: In conclusion, this study established the anti-oxidant and anti-inflammatory activities of Bougainvillea $x$ buttiana (var. Rose); also, this extract could be considered to be a natural anti-oxidant agent that represents an anti-inflammatory remedy.

Keywords: Anti-inflammatory, Antioxidant, Phenolic compound

(C) 2016 The Authors. Published by Innovare Academic Sciences Pvt Ltd. This is an open access article under the CC BY license (http://creativecommons.org/licenses/by/4.0/) DOI: http://dx.doi.org/10.22159/ijpps.2017v9i3.16190

\section{INTRODUCTION}

Different reports from the World Health Organization have shown that approximately $80 \%$ of the world population depends on traditional medicine for their primary healthcare needs. Plants contain numerous biologically active compounds; recently, different studies have shown that phytochemical compounds are of great interest to the pharmaceutical industry according to their antiinflammatory, anti aging, and antimicrobial properties. These biological activities make them an important source of molecules for new drug discovery [1]. Many plants for medicinal use and their purified components have displayed therapeutic potential. The identification of chemical compounds present in plants is important for the discovery of new agents for therapeutic use, and this information can be of great value to the development of economic phytol compounds that can be used in complex chemical synthesis [2]. To obtain this information, mass spectrometry coupled with chromatographic separations, such as gas chromatography (GC/MS), is generally used for direct analysis of constituents present in traditional medicine and medicinal plants.

The genus Bougainvillea is a broad genus that belongs to the Nyctagineacea Family and is widely used in traditional medicine for treating respiratory infections; antibacterial, antiviral, and antifertility activities; and diarrhoea as well as to reduce stomach acidity $[3,4]$. For example, $B$. spectabilis and B. glabra were highly effective in reducing virus infection $[3,4]$. In these genera, other activities were observed, such as anti-inflammatory activity [5]; also, they have been identified to control and prevent diabetes $[6,7]$.

The Bougainvillea genus is extensively dispersed in Cuernavaca, Morelos, Mexico, such as Bougainvillea x buttiana. We previously showed that Bougainvillea $x$ buttiana (var. Orange) extract has antiinflammatory and anti-nociceptive activities [8]. Bougainvillea from different colours and regions has been reported to exhibit antioxidant activity [9].

The purpose of the present study was to identify the chemical composition of ethanol extract from B. $x$ buttiana (var. Rose; Holttum and Standel) and to estimate its antioxidant and anti-inflammatory activities.

\section{MATERIALS AND METHODS}

Chemicals and solvents

Ethanol, gallic acid (GA), and carrageenan were purchased from Sigma-Aldrich Chemical Co., (Toluca, Mexico).

\section{Animals}

Animals were purchased from Bioterio del Instituto Nacional de Salud Pública (Cuernavaca-Morelos, México). BALB/c female mice (20-25 g) were used for all experiments. The animals used for the experiments were treated in accordance with the protocol approved by the Committee for Animal Care (Facultad de Medicina Universidad Autónoma del Estado de Morelos, Cuernavaca, Mexico) (CCUAL-FM-UAEM Number 002/2016).

\section{Extraction of plant material}

The flowers and bracts of Bougainvillea $x$ buttiana were manually harvested in Cuernavaca, Morelos, Mexico during summer 2015 and identified. A voucher specimen Bougainvillea $x$ buttiana (Holttum and Standl) was registered with foil 33870 for later reference and deposited at the Herbarium HUMO, CIByC 
(UAEM). The plant collection included $110 \mathrm{~g}$ of flowers and bracts that were dehydrated at $25^{\circ} \mathrm{C}$, ground into powder and submerged at a ratio of $50 / 50(\mathrm{w} / \mathrm{v})$ for $3 \mathrm{~d}$ with continuous shaking. The extract was filtered through Whatman filter paper $\mathrm{N}^{\circ} 1$, and the solvent was removed using a rotary evaporator at $50{ }^{\circ} \mathrm{C}$. The crude ethanolic extract of Bougainvillea $\mathrm{x}$ buttiana (var. Rose) was named (BxbREE) and stored at-20 ${ }^{\circ} \mathrm{C}$ for screening anti-inflammatory activity.

\section{Phytochemical quantitative analysis}

The phytochemical screening methods for detecting the compounds in the ethanolic extract of Bougainvillea $x$ buttiana were performed as per standard methods [10].

\section{Carbohydrates}

To detect the presence of carbohydrates, the Fehling test with the colorimetric method was used as described by Aziz, 2015 [11]. The following equation was based on the calibration curve: $\mathrm{Y}=2.0275 \mathrm{X}-$ $0.1023 \mathrm{R}^{2}=0.9803$, where $\mathrm{X}$ is the absorbance and $\mathrm{Y}$ is in $\mathrm{mg} / \mathrm{ml}$. Each test was performed in quadruplicate.

\section{Lipids}

The quantification of lipids present in ethanolic extracts of BxbREE was performed by a simple colourimetric method as described by Mishra et al., 2014 [12]. The following equation was based on the calibration curve: $\mathrm{Y}=1.1148 \mathrm{X}-0.0043 \mathrm{R}^{2}=1$, where $\mathrm{X}$ is the absorbance and $\mathrm{Y}$ is in $\mathrm{mg} / \mathrm{ml}$. Each test was performed in quadruplicate.

\section{Total phenolic content (TPC)}

The total phenolic levels present in ethanolic extracts of $B . x$ buttiana were assayed using the method of Folin-Ciocalteau phenol as reported by Singleton et al., 1999 [13]. The TPC was expressed in terms of gallic acid (equivalents of GA/gram of dried extract). The following equation was based on the calibration curve: $\mathrm{Y}=7.3526 \mathrm{X}-0.0026 \mathrm{R}^{2}=0.9993$, where $\mathrm{X}$ is the absorbance and $Y$ is in $\mathrm{mgGA} / \mathrm{g}$. Each sample was evaluated in quadruplicate.

\section{GC-MS analysis}

GC-MS was performed at Centro de Investigaciones QuímicasUAEM; analyses were performed using an Agilent 6890B gas chromatograph fitted with an HP-5MS fused silica column $(5 \%$ phenyl methyl polysiloxane $30 \mathrm{~m}$ x $0.25 \mathrm{~mm}$ i.d., film thickness 0.25 $\mu \mathrm{m})$ that was interfaced with an Agilent mass selective detector 5973N (Agilent Technologies, USA) and operated by HP Enhanced ChemStation software. For GC-MS detection, an electron ionization system with an ionization energy of $70 \mathrm{eV}$ was used.

Helium was used as the carrier gas at a flow rate of $1 \mathrm{ml} / \mathrm{min}$. The injector and transfer line temperatures were set at 250 and $285^{\circ} \mathrm{C}$, respectively. The column temperature was initially kept at $10^{\circ} \mathrm{C}$ for 1 minute and was then gradually increased to $250^{\circ} \mathrm{C}$ at a rate of 5 ${ }^{\circ} \mathrm{C} / \mathrm{min}$; finally, it was raised to $285^{\circ} \mathrm{C}$ at a rate of $1{ }^{\circ} \mathrm{C} / \mathrm{min}$.
A diluted sample in DMSO (20\% solution) of $2.0 \mu \mathrm{l}$ was injected in split mode at a ratio of 1:50. The chromatographic conditions and column used for GC analyses (Agilent 5973N gas chromatograph with FID detector) were the same as those for GC-MS analyses. The identity of the components of the essential oil was selected by comparison on the HP-5MS column and GC-MS spectra from the Wiely7Nist data by co-injection with authentic compounds (Sigma, Aldrich, Fluka). Quantification of the components was performed on the basis of their GC peak areas on the HP-5MS column.

\section{Acute oral toxicity study}

Female BALB/c mice were dosed via a stepwise procedure using fixed doses of $4,40,400,800$, and $1600 \mathrm{mg} / \mathrm{kg}$ of body weight in mice [14]. After treatment with extract, the animals were individually observed for any toxic manifestations as well as up to a period of $2 \mathrm{w}$ for mortality and general behaviour [15]. The observed parameters were the skin, fur, eyes, mucous membranes, tremors, convulsions, salivation, diarrhoea, lethargy, sleep and coma; respiratory, circulatory, autonomic and central nervous systems; somatomotor activity; and behaviour patterns.

\section{Edema paw}

The animals were divided into 18 different groups ( $\mathrm{n}=4$ each group). The ethanol extract of BxbREE (0.04; 0.4; 4; and $40 \mathrm{mg} / \mathrm{kg}$ ) was orally, intraperitoneally and/or subcutaneously administered to different groups of mice. The standard drug indomethacin, Aspirin ${ }^{\circledR}$ and dexamethasone $(4 \mathrm{mg} / \mathrm{kg})$ was administered intraperitoneally.

To evaluate acute inflammation, mice were treated with a subplantar injection of $100 \mu \mathrm{l}$ of a $1 \%$ suspension of carrageenan in the right hind paw [16]. The paw volume was measured initially and then every $15 \mathrm{~min}$ for up to $24 \mathrm{~h}$. After carrageenan injection, the edema volume was determined using the plethysmographic method [17]. Edema inhibition percentage (\%EI) was calculated using the following formula:

$$
\% \mathrm{EI}=[1-(\mathrm{Vt} / \mathrm{Vc}) \mathrm{X} 100]
$$

Where: $\mathrm{Vt}=$ volume paw from treated animals and $\mathrm{Vc}=$ volume paw from control animals.

\section{Statistical analyses}

The results are presented as the means \pm standard deviation. Statistical analyses of the experimental results were based on analysis of variance (ANOVA), which was complemented by GraphPad Prism 6. Differences were considered significant at the $\mathrm{p}<0.05$ level.

\section{RESULTS}

\section{Phytochemical analyses}

Table 1 shows the results of the quantitative phytochemical analysis of the ethanolic extract from BxbREE. These analyses revealed the presence of carbohydrates, lipids and total phenolic contents.

Table 1: Quantitative analysis of ethanolic extract of BxbREE

\begin{tabular}{ll}
\hline Pythochemical & Levels $/ \mathbf{g}$ dry extract $\mathbf{( m g / m )}$ \\
\hline Carbohydrates & $5.18 \pm 0.02$ \\
Lipids & $13.88 \pm 0.03$ \\
Total Phenolic Contents & $320.00 \pm 19.20^{*}$ \\
\hline
\end{tabular}

Each value represents the mean \pm SD $(n=4) .{ }^{*}$ The TPC was expressed in terms of gallic acid (equivalents of GA/gram of dried extract).

\section{GC-MS analysis}

The results obtained from the GC-MS analysis showed the presence of 7 compounds in the ethanolic extract of Bougainvillea $x$ buttiana (table 2). Two of the compounds belong to the chemical group of phenolic compounds, such as 2-Propenoic acid, 3-(2- hydroxy-phenyl)-, (E)-(1.19\%) and 2-Methoxy-4-vinylphenol $(0.22 \%)$. One of them is carbohydrate 3-0-Methyl-d-glucose $(92.14 \%)$, and the following 4 are fatty acids: $n$-Hexadecanoic acid $(0.760 \%)$; Hexadecanoic acid, ethyl ester (1.17\%); 9,12Octadecadienoic acid, ethyl ester (1.93\%); and 9,12,15Octadecatrienoic acid, ethyl ester (Z,Z,Z) (2.59\%). 
Table 2: Phytocompounds identified in the ethanolic extract of Bougainvillea $x$ buttiana by GC-MS

\begin{tabular}{|c|c|c|c|c|c|}
\hline Number & Chemical groups & Compounds & Molecular weigh (g/mol) & RT (min) & GC area \% \\
\hline 1 & Phenolic compound & 2-Propenoic acid, 3-(2-hydroxyphenyl)-, (E)- & 164.16 & 10.57 & 1.19 \\
\hline 2 & Phenolic compound & 2-Methoxy-4-vinylphenol & 150.18 & 11.93 & 0.22 \\
\hline 3 & Carbohydrate & 3-0-Methyl-d-glucose & 194.18 & 16.76 & 92.14 \\
\hline 4 & Fatty acid & $n$-Hexadecanoic acid & 256.48 & 19.32 & 0.76 \\
\hline 5 & Fatty acid & Hexadecanoic acid, ethyl ester & 284.48 & 19.66 & 1.17 \\
\hline 6 & Fatty acid & 9,12-Octadecadienoic acid, ethyl ester & 308.49 & 21.25 & 1.93 \\
\hline 7 & Fatty acid & $9,12,15$-Octadecatrienoic acid, ethyl ester $(\mathrm{Z}, \mathrm{Z}, \mathrm{Z})$ - & 306.49 & 21.32 & 2.59 \\
\hline
\end{tabular}

Table 3 shows the phytochemicals that contribute to the medicinal properties of the plant. Phenolic compounds, such as the 2Propenoic acid, 3-(2-hydroxyphenyl)-, (E)-and 2-Methoxy-4vinylphenol, are reported to have anti-oxidant, anti-inflammatory and anti-bacterial activities. There were also other compounds with antioxidant activity, such as $n$-Hexadecanoic acid and Hexadecanoic acid ethyl ester. Another component with anti-inflammatory activity was 9, 12, 15-Octadecatrienoic acid, ethyl ester (Z,Z,Z). Cell preservation activity is reported for 3-0-Methyl-d-glucose; finally, anti-parasitic activity was reported for 9, 12-Octadecadienoic acid ethyl ester [Chemical structure, Marvin 15.11.23, 2015, ChemAxon (http://www.chemaxon.com].

Table 3: Activity of photo components identified in the ethanolic extract of Bougainvillea $\mathrm{x}$ buttiana by GC-MS

\begin{tabular}{|c|c|c|}
\hline Number & Chemical structure & Activity \\
\hline 1 & $\begin{array}{l}\text { 2-Propenoic acid, 3-(2-hydroxyphenyl)-, } \\
\text { (E)- } \\
\text { HO YO }\end{array}$ & $\begin{array}{l}\text { Antibacterial, flavor, Aldose-Reductase-Inhibitor, Allergenic, Anesthetic, Antiinflammatory, } \\
\text { Antimutagenic, Antispasmodic, Cancer Preventive; Choleretic; Dermatitigenic, Fungicide, } \\
\text { Herbicide, Laxative, Pesticide, Lipoxygenase-Inhibitor, Pesticide, TyrosinaseInhibitor and } \\
\text { Vermifuge [18]. }\end{array}$ \\
\hline 2 & 2-Methoxy-4-vinylphenol & Antioxidant, Antimicrobial and Anti-inflammatory [19]. \\
\hline 3 & 3-0-Methyl-d-glucose & Preservative [20]. \\
\hline 4 & n-Hexadecanoic acid & $\begin{array}{l}\text { Antioxidant, Pesticide, Flavor, 5-Alpha reductase-inhibitor, Antifibrinolytic, Hemolytic, } \\
\text { Lubricant, Nematicide and Antialopecic [18]. }\end{array}$ \\
\hline 5 & Hexadecanoic acid, ethyl ester & Antioxidant [18]. \\
\hline 6 & $\begin{array}{l}\text { 9,12-Octadecadienoic acid, ethyl ester } \\
\mathrm{H}_{3} \mathrm{C}\end{array}$ & $\begin{array}{l}\text { Hypocholesterolemic, Nematicide Antiarthritic, Hepatoprotective Anti androgenic, } \\
\text { Hypocholesterolemic Nematicide, 5-Alpha reductase inhibitor, Antihistaminic, } \\
\text { Anticoronary Insectifuge, Antieczemic and Antiacne [21]. }\end{array}$ \\
\hline 7 & $\begin{array}{l}\text { 9,12,15-Octadecatrienoic } \\
\text { acid, ethyl ester (Z,Z,Z)- }\end{array}$ & $\begin{array}{l}\text { Antiinflammatory, Insectifuge Hypocholesterolemic, Cancer preventive, Nematicide, } \\
\text { Hepatoprotective, Insectifuge, Antihistaminic, Antieczemic, Antiacne, 5-Alpha reductase } \\
\text { inhibitor, Antiandrogenic, Antiarthritic and Anticoronary [20]. }\end{array}$ \\
\hline
\end{tabular}

\section{Acute toxicity studies}

During the period of up to $2 \mathrm{w}$, no mortality or behavioural changes were observed. The ethanol extract was secured to a dose of 1600 $\mathrm{mg} / \mathrm{kg}$ body weight. In accordance with this test, BxbREE was tested at 0.04 up to $40 \mathrm{mg} / \mathrm{kg}$ body weight for further experiments.

Anti-inflammatory activity of the BxbREE extract using carrageenan-induced rate paw edema in an animal model

To determine the anti-inflammatory activity of the ethanolic extract BxbREE, groups of mice were treated with different concentrations and administration routes and analysed in the carrageenan model. Fig. 1 shows the anti-inflammatory properties of an ethanolic extract from BxbREE administered by different routes. The paw volume was significantly reduced in all tests with the extract. For all routes of administration at doses ranging from 0.04 to 0.4 , the highest percentage of edema inhibition was observed at $4 \mathrm{~h}$, which decayed thereafter. In contrast, at doses of 4 and $40 \mathrm{mg} / \mathrm{kg}$ in groups of animals with intraperitoneal treatment, there was an increase in the percentage inhibition at $12 \mathrm{~h}$. The extract presented a potent dosedependent inhibitory effect. In groups of animals that were treated via intraperitoneal or subcutaneous administration, the extract was 1.24 or 1.56 times less effective via oral administration.

In the carrageenan assay, edema and inflammation are induced by biphasic events. Indomethacin, aspirin and dexamethasone are used as positive controls; also, at a dose of $4 \mathrm{mg} / \mathrm{kg}$, there was markedly reduced paw edema in the carrageenan model $(\mathrm{p}<0.001)$. When BxbREE was orally administered, it was equally potent in inhibiting carrageenan edema (fig. 1). 
$0.04 \mathrm{mg} / \mathrm{kg}$

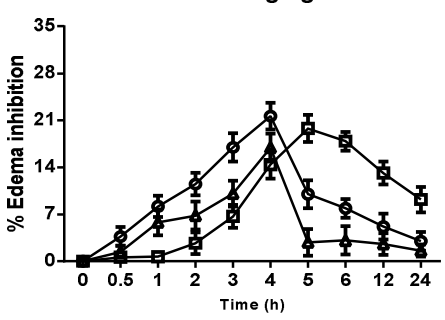

$4 \mathrm{mg} / \mathrm{kg}$

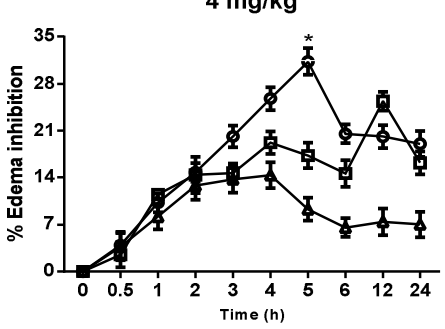

$0.4 \mathrm{mg} / \mathrm{kg}$

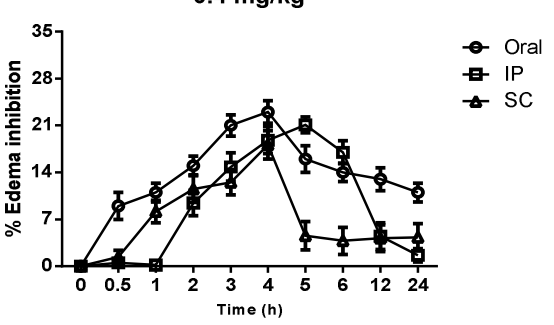

$40 \mathrm{mg} / \mathrm{kg}$

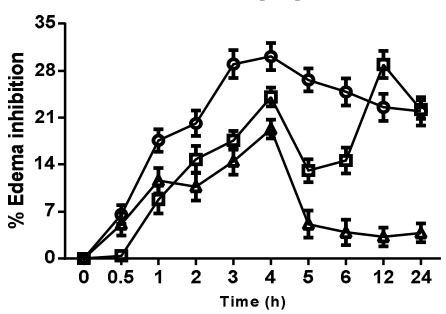

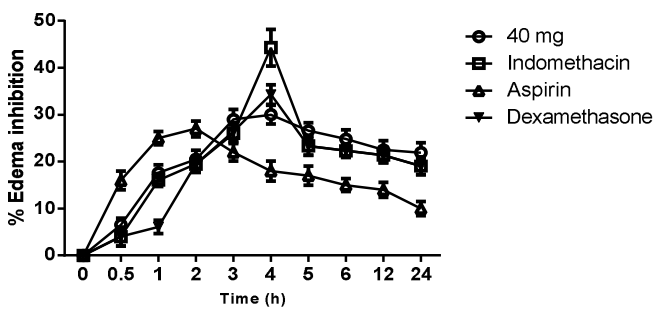

Fig. 1: Percent of oedema inhibition. Groups of BALB/c female mice were treated with different concentrations of BxbREE over the course of $24 \mathrm{~h}$. To compare the percent inhibition of edema for standard drugs, such as indomethacin, aspirin and dexamethasone, groups of mice were treated intraperitoneally with $4 \mathrm{mg} / \mathrm{kg}$, which was compared with groups of mice treated with $40 \mathrm{mg} / \mathrm{kg}$ BxbREE. Each point represents the mean \pm SD $n=4$ mice $(p<0.001)$

\section{DISCUSSION}

Phenolic compounds present in plants are an extensive group with a broad spectrum of biological activities, such as anti-inflammatory, antiviral, antimicrobial, antioxidant, anti-mutagenic, and anticarcinogenic activities, and they modify gene expression. They have also been highlighted for their contribution towards lowering the risks of diverse diseases, especially for coronary heart and pulmonary diseases as well as for different cancer types [22-25]. With respect to tannins, they can antagonise the effects of permeability in rats and inhibit the migration of leucocytes to an inflamed site. Recently, different studies have shown that phenol compounds and flavonoids are of high interest to the pharmaceutical industry because of their anti-inflammatory, anti-aging, and antimicrobial benefits, which make them an important source of molecules for new drug discovery [1].

Based on these results, the BxbREE extract had a pharmacological effect that may be due to the synergistic effects of the various compounds present in the crude extract. The bioactivities of various compounds, such as phenolic contents, fatty acids, and carbohydrates, are responsible for their antioxidant, anticarcinogenic, anti-mutagenic and anti-inflammatory properties [26].

The carrageenan model is characterised by the liberation of different mediators at two phases. The first phase, at 1 hour after carrageenan injection, is characterised by the liberation of histamine and serotonin. The kinnins correspond to the continuity between the two phases [25]. The second phase, from 2.3 to $6 \mathrm{~h}$, is mediated by prostaglandins and cyclooxygenase [25]. The present study clearly demonstrated that BxbREE at doses of 4 and $40 \mathrm{mg} / \mathrm{kg}$ significantly reduced the oedema formation induced by carrageenan at all assessment time periods. There are several components to an inflammatory response that may contribute to its associated symptoms and promote tissue regeneration, including oedema, granuloma formation and leukocyte infiltration. The intensity of the inflammatory response is crucial when there is an insufficient response, which can lead to immunodeficiency, and an excessive response, which increases morbidity and mortality. However, the imbalance of an inflammatory response can cause organ damage or dysfunction and contribute to the host's mortality [27].

Acute inflammation is a rapid event that has a short duration, lasting from minutes to days. It is characterized by exudation of fluid and plasma protein as well as an accumulation of leukocytes and involves cellular influx that is associated with the release of mediators [28]. On the other hand, chronic inflammation may be more critical or dangerous because it occurs over a longer time period (days to years) and is characterized by an influx of lymphocytes and macrophages, which is associated with vascular proliferation and fibrosis [27].

\section{CONCLUSION}

In conclusion, this study scientifically validated that the ethanolic extract of BxbREE (var. Rose; Holttum and Standl) has potent antioxidant and anti-inflammatory activities. These effects might be attributed to the detected compounds in ethanol extract. These results showed that the $B . x$ buttiana extract could be considered to be a natural anti-oxidant agent and acts as an anti-inflammatory remedy.

\section{ACKNOWLEDGMENT}

This work was supported by the Secretaria de Educación Pública (SEP-PRODEP)-México and Consejo Nacional de Ciencia y 
Tecnología (CONACyT-México). The authors are grateful for the technical support of Master in Science Claudia García Alanis.

\section{CONFLICT OF INTERESTS}

\section{Declared none}

\section{REFERENCES}

1. Cos P, Vlietinck AJ, Berghe DV, Maes L. Anti-infective potential of natural products: how to develop a stronger in vitro 'proofof-concept'. J Ethnopharmacol 2006;106:290-302.

2. Milne A. Inhalational and local anesthetics reduce tactile and thermal responses in Mimosa pudica linn. Masui 1993;2:1190-3.

3. Balasaraswathi R, Sadasivam S, Ward M, Walker JM. An antiviral protein from Bougainvillea spectabilis roots; purification and characterization. Phytochemistry 1998; 47:1561-5.

4. Pun KB, Sabitha D, Jeyarajan R. Screening of plants species for the presence of antiviral principles against okra yellow vein mosaic virus. Indian J Phytopathol 1998;52:221-3.

5. Joshi DD, Mujumdar AM, Narayanan CR. Anti-inflammatory activity of Bougainvillea spectabilis leaves. Indian J Pharm Sci 1998;46:187-8.

6. Davidson MB, Peters AL, Schringer DS. An alternative approach to the diagnosis of diabetes with a review of the literature. Diabetes Care 1998;8:1065-71.

7. Mishra N, Joshi S, Tandon VL, Munjal A. Evaluation of antifertility potential of Bougainvillea spectabilis leaves in swiss albino mice. Int J Pharm Sci Drug Res 1998;1:19-23.

8. Alvarez Perez Gil AL, Barbosa Navarro L, Patipo Vera M, Petricevich VL. Anti-inflammatory and aninocieptive activites of the ethanolic extract of Bougainvillea xbuttiana. J Ethnopharmacol 2012;144:712-9.

9. Arteaga Figueroa L, Barbosa Navarro L, Patiño Vera M, Petricevich VL. Antioxidant activity, total phenolic and flavonoid contents, and cytotoxicity evaluation of Bougainvillea xbuttiana. Int J Pharm Pharm Sci 2014;6:498-502.

10. Dominguez XA. Métodos de Investigación Fitoquímica, Limusa, Mexico City, México; 1985.

11. Aziz MA. Qualitative phytochemical screening and evaluation of anti-inflammatory, analgesic and antipyretic activities of Microcos paniculata barks and fruits. J Integr Med 2015;13:173-84.

12. Mishra SK, Suh WI, Farooq W, Moon M, Shrivastav A, Park MS, et al. Rapid quantification of microalgal lipids in an aqueous medium by a simple colorimetric method. Bioresour Technol 2014;155:330-3.

13. Singleton VL, Orthofer R, Lamuela-Raventos RM. Analysis of total phenols and other oxidation substrates and antioxidants by means of folin-ciocalteu reagent. Methods Enzymol 1999;299:152-78.
14. OECD. Guidance document on the recognition, assessment and use of clinical signs as humane endpoints for experimental animals used in safety evaluation. Environmental Health and Safety Monograph Series on Testing and Assessment N ${ }^{\circ} 19$, ENV/JM/MONO; 2000.

15. Olufunmilayo 0, Adeyemi SO, Okpo 00. The analgesic effect of methanolic extract of Acanthus montanus. J Ethnopharmacol 2004;90:45-68.

16. Winter CA, Risley EA, Nuss CW. Carrageenan-induced oedema in hind paw of the rat as an assay for anti-inflammatory drugs. Proc Soc Exp Biol Med 1962;111:544-7.

17. Mujumdar AM, Misar AV. Anti-inflammatory activity of Jatropha curcas roots in mice and rats. J Ethnopharmacol 2004;90:11-5.

18. Ponnamma SU, Manjunath K. GC-MS analysis of phytocomponents in the methanolic extract of Justicia wyaadensis (NEES) T. Anders. Int J Pharma Bio Sci 2012;3:570-6.

19. Jin BJ, Se CH, Hyung JJ, Jin SK. Anti-inflammatory effect of 2methoxy-4-vinylphenol via the suppression of NF- $\mathrm{kB}$ and MAPK activation, and acetylation of histone H3. Arch Pharmacol Res 2011;34:2109-16.

20. Sermakkani M, Thangapandian V. GC-MS analysis of Cassia italic leaf methanol extract. Asian J Pharm Clin Res 2012;5:90-4.

21. Jananie RK, Prya V, Vijayalakshmi K. Determination of bioactive components of Cynodon dactylon by GC-MS analysis. New York Sci J 2011;4:16-20.

22. Frydoonfar HR, McGrath DR, Spigelman AD. The variable effect on proliferation of a colon cancer cell line by the citrus fruit flavonoid naringenin. Colorectal Disease 2003;5:149-52.

23. Hakimuddin F, Paliyath G, Meckling K. Selective cytotoxicity of a red grape wine flavonoid fraction against MCF-7 cells. Breast Cancer Res Treat 2004;85:65-79.

24. Reddy KS, Katan MB. Diet, nutrition and the prevention of hypertension and cardiovascular diseases. Public Health Nutr 2004;7(1a):167-86.

25. Queiróz RF, Jordão $A K$, Cunha AC. Nitroxides attenuate carrageenan-induced inflammation in rat paws by reducing neutrophil infiltration and the resulting myeloperoxidasemediated damage. Free Radical Biol Med 2012;53:1942-53.

26. Huang WY, Cai YZ, Zhang Y. Natural phenolic compounds from medicinal herbs and dietary plants: potential use for cancer prevention. Nutr Cancer 2010;62:1-20.

27. Kumar V, Abbas AK, Fausto N, Mitchell RN. Acute and Chronic Inflammation. In: Robbins Basic Pathology: Eighth Edition Saunders Elsevier. Philadelphia; 2007. p. 31-2.

28. Flower RJ, Perretti M. Controlling inflammation: a fat chance? J Exp Med 2005;201:671-4.

\section{How to cite this article}

- $\quad$ Rigoberto Villanueva Guerrero, Rodolfo Abarca-Vargas, Vera L Petricevich. Chemical compounds and biological activity of an extract from bougainvillea $x$ buttiana (var. rose) holttum and standl. Int J Pharm Pharm Sci 2017;9(3):4246. 